\title{
$\mathrm{USN}$ 을 활용한 교통제어기의 연동시스템 구현
}

\author{
진현수 \\ 백석대학교 정보통신학부
}

\section{Implementation of Linkage System of Traffic Applied USN}

\author{
Hyun-Soo Jin \\ Div. of Information Communication, Baekseok University
}

\begin{abstract}
요 약 교통의 연동시스템은 이웃한 교차로의 교통상황을 입력받아 해당 교차로 신호처리시 고려하는 시스템이다. 이웃 교차로의 통과차량수, 대기차량수,녹색신호등 주기 등을 감안하여 해당 교차로의 녹색신호등의 주기를 결정하는 형태이다. 해당교차로의 녹색신호등을 고려할 때는 자기 자신의 센서 입력들만 고려해서는 안되고 이웃 교차로의 센 서 입력들을 받아 들여야 한다. 이러한 센서 노드들의 데이터 수집을 위해서 위험과 한계가 있는 곳에 센서 노드를 배치하여 데이터 수집을 하는 경향을 감안하여 사람이 인접할수 없는 곳이나 환경이 척박한곳에 센서들을 배치하여 센서들을 통한 정보 획득, 무선 네트워크를 통한 통신,초저전력 소모를 실현할 수 있다.
\end{abstract}

주제어 : 네트워크 기술, 집적 기술, 대규모 네트워크,센서 노드

\begin{abstract}
Traffic network is composed of passing vehicls, delayed vehicles, traffic situation which is traffic incomes of traffic interfacing system. Traffic green time light is concluded by inside input factor, that is green light cycle, yellow light cycle, led light cycle, which light cycle is sensor inputs. That light cycle is converted to traffic phase composed of passing peoples and delayed vehicles, whose intervals is concluding of traffic network factors composed of consumptiom power factors, delayed time situation, occupying sensor nodes. This is very important sector,because of much poor traffic situation.
\end{abstract}

Key Words : Network Technique, Imbeded Technique, Very Large Network, Sensor Node

\section{1. 서론}

교통량을 선택하여 센서를 구성하고자 한다면 센서 네트워크의 특성을 알아야만 한다. 많은 숫자의 센서노 드를 배치하여 대규모 데이터 망을 구축한다. 이는 노드 당 가격이 저렴하므로, 대규모 센서 네트워크의 구현이 용이하기 때문에 가능하는 일이다. 이때 일부 노드에 결
함이 발생하여도 다른 경로를 통하여 네트워크의 기능을 유지할 수 있는 일이다[1]. 센서노드는 저전력 무선 센서 노드를 사용하는데 무선 프로토콜 및 라우팅이 용이하다. 또한 소프트웨어를 통하여 분산알고리즘의 동적 수용이 가능하다. 또한 분산 모니터링과 망관리가 용이하고 중 앙의 웹기반 모니터링 도구를 사용할 수 있다. 제한된 자 원의 사용을 할 수가 있는데 프로세싱및 저장. 대역폭, 전
* 본 논문은 2014년 백석대학교 학술연구비에 의하여 지원되었음

Received 14 April 2014, Revised 21 May 2014

Accepted 20 July 2014

Corresponding Author: Hyun-Soo Jin(Div. of Information Communication, Baekseok University)

Email: jhs1020@bu.ac.kr

ISSN: $1738-1916$
(C) The Society of Digital Policy \& Management. All rights reserved. This is an open-access article distributed under the terms of the Creative Commons Attribution Non-Commercial License (http://creativecommons.org/licenses/by-nc/3.0), which permits unrestricted non-commercial use, distribution, and reproduction in any medium, provided the original work is properly cited. 
력의 사용을 기할 수 있다. 수많은 노드에 뿌려진 응용 센서를 통하여 데이터를 자가수집할 수 가 있으며 변화 하는 네트워크 환경에서의 적응을 기할 수 있으며 병목 현상을 처리 할 수가 있다[2]. 즉 센싱 데이터와 네트워크 트래픽등 스케줄링 관리가 용이하다. 사용처로는 기반기 술이 거의 없는곳에 사용되는데 채광현장,건설현장,위험 한 환경, 농작물의 경작지에 이용할 수 가 있다. 또한 응 용할 수 있는 분야로서 자산 이동 환경 변화 등에 대한 실시간 데이터가 거의 없거나 전무 한 곳, 재고 및 공급 등의 관리로서 제약분야및 냉동 식품등에 사용하고 자동 화된 계량 시스템에 응용할 수 가 있다[3].

센서의 구성목적이 자동차를 검증하는 단계이므로 루 프센서를 사용하여 자동차의 주행속도를 파악하였다.

\section{2. 본론}

\section{1 실험환경}

실험 모듈인 HMOTE2420의 MCU와 RF Chip은 T1 사의 msp430f161와 $\mathrm{CC} 2420$ 을 사용하여 제작되었 다.Tinyos-1.x/Tinyos -2.x/Nano-Qplus/RETOS 등의 $\mathrm{OS}$ 를 올려 테스트 했으며,USB를 통하여 이미지 업로드 및 모니터링이 가능하다. Two-level schedular를 사용하 여 $\mathrm{MPR} 400 \mathrm{CB}$ 를 하드웨어로 장착하여 구현시킨다[4]. 구현된 시스템은 2 위상 1 대역 주파수로 가동된다. 하드 웨어 구성을 양방향성 Provider와 user로서 구성한다. 데 이터의 이동은 인터페이스 구성으로서 성립되는 조직이 기초이다. 이코드는 실제로서 존재하지 않는다. 여기에서 Provider는 커멘드를 수행하고 user는 이벤트를 수행한 다. 모듈은 함수 Implementation \{\} 에 제공된 커멘드나 이벤트를 구현할수있다. call이나 시그날의 표현에 의해 서 수행되어지는 실제의 커멘드나 이벤트 구현들은 프로 그램의 configuration에서 wiring statement에 의존한다[5].

소프트웨어 구성은 syntax구조로는 파일 이름은 상위 계층 사양으로서 xxx..nc로 사용을 하고 일반적 사양으 로서는 $\mathrm{xxxC.nc로} \mathrm{구성한다[6].}$
〈Table 1〉 Range of channel width

\begin{tabular}{|c|c|}
\hline standard market & Wi-Fi \\
\hline \hline application system & web, E-mail,Video \\
\hline source system & $1 \mathrm{MB}$ \\
\hline length of network & 32 \\
\hline channel width & 11,000 \\
\hline transfer range & velocity \\
\hline merit point & Zigbee \\
\hline Bluetooth & monitering \& control \\
\hline cable selecting & $25 \mathrm{~KB}-50 \mathrm{~KB}$ \\
\hline channel length & $255 / 65,000$ \\
\hline 7 & $20-250$ \\
\hline 720 & $1-100$ \\
\hline $1-10$ & power, resistance \\
\hline cost,conductance
\end{tabular}

운영체제로 쓰이는 TinyOS의 블링크를 분석하여 보 면 인터페이스의 와이어링결합으로 구성되었으며 인터 페이스의 using과 providing의 운영체제로 사용되어 커 멘드와 이벤트의 구현으로 구성되어진다. 와이어링 상태 는 양방향성이고 실제 코드는 존재하지 않는다.

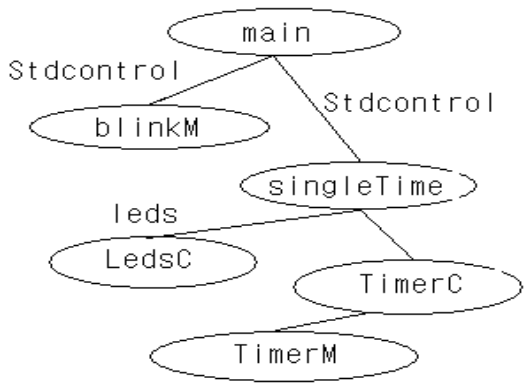

[Fig. 1] Environment of experiment Model

디렉토리 구조로서는 제일 최상위에 Root 디렉토리의 $\mathrm{APPs}$ 에 어플리케이션의 Mote가 존재하고 $\mathrm{DOC}$ 밑에는 Documents가 Tutorial과 nes DOC와 함께 존재한다. $\mathrm{DOC}$ 위에는 Tools가 존재하여 java 클래스가 $\mathrm{pc}$ 호스 트안에 존재하듯이 상주한다[7].

TOS 교차로 A,B,C의 주콘트롤 박스에 유비쿼터스 센서를 부착하여 교차로 마다 신호를 송수신하여 신호의 유무를 탐지하여 교차로 신호 판넬간에 새로운 신호를 송수신하여 신호 유무를 감지하는 것이다.

Wlan 802.11와 Wpan 802.15군의 상징적인 비교를 통 해 각 통신군의 성능을 비교한다. 


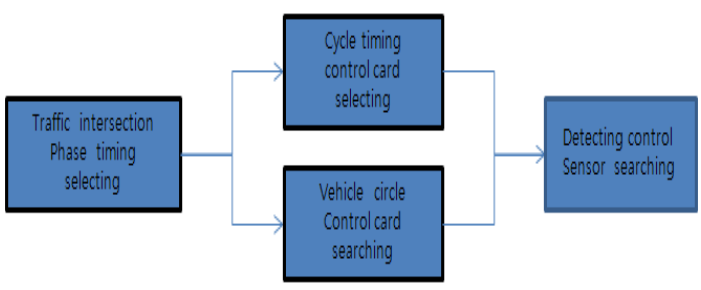

[Fig. 2] Traffic volume of control card

MICA2의 메시지를 보내는 방법은 TinyOS의 메시지 가 스택을 돌고나올때 유전알고리즘칸을 선택하고 $\mathrm{AM}$ 조작기는 헤더칸을 구축하고 소스어드레스와 $\mathrm{AM}, \mathrm{ID}$ 어 드레스를 향해 프로세스를 진행한다.

무선진행파와 UART 통신채널을 구축하고 무작위 지 연은 15 개의 패킷시간동안까지 다다른다.

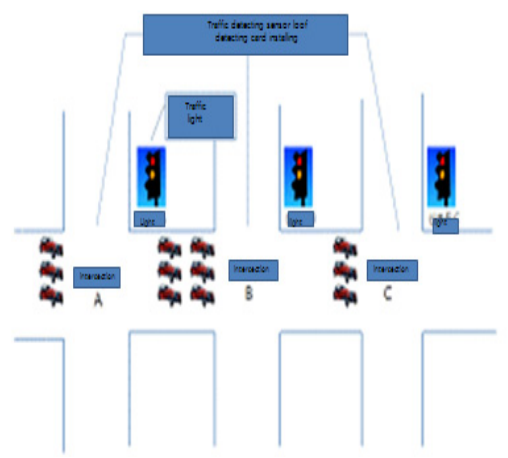

[Fig. 3] Traffic situation of intersection model

TinyOS의 구조 개념과 실행모델을 구체화 하기 위해 디자인된 $\mathrm{C}$ 언어의 확장으로서 동적인 메모리 할당은 없 다.C언어의 확장된 개념은 마이크 충돌회피현상을 $\mathrm{CSMA}$ 로 저장한후 전송기를 전환하여 SPI포트가 끝날 때 까지 패킷을 보낸다

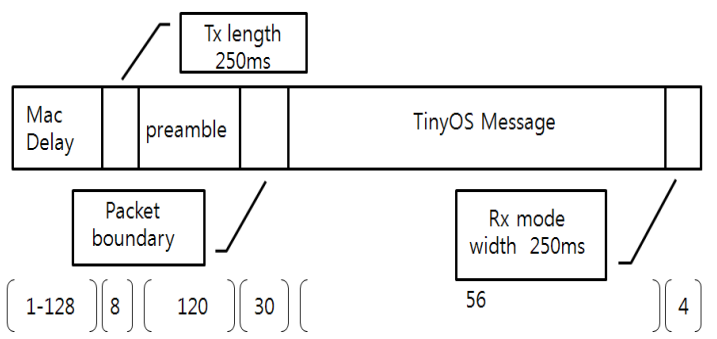

[Fig. 4] Frequency of traffic situation
컨트롤러를 위한 효율적인 코드를 개발하고 구성시키 기 위해서는 $\mathrm{C}$ 코드와 상호 작용, 사용 할 수 있다. 이는 많은 $\mathrm{C}$ 프로그래머가 있기 때문에 개발 소스 공유및 사 용이 용이하다. 컴퍼넌트와 인터페이스의 구조는 양방향 성을 띠고 있다. 그중 컴퍼넌트의 사양으로서는 모듈이 컴퍼넌트의 구현이 $\mathrm{C}$ 코드에 의해서 제공되고 구현사실 은 커넥트,와이어, 다른 컴퍼넌트를 함께 모음으로 컴퍼 넌트의 규격을 구현한다. 정적 구현 상태로는 동적 메모 리가 존재하지를 않고 함수 포인터가 있지를 않다.프로 그래밍 상태로는 플래쉬 메모리가 128 kbyte 이고 SRAM은 $4 \mathrm{~K}$ byte이다 EEPROM은 4Kbyte이다. 소프트 웨어 상으로서는 모듈이 XxxM.nc 사양을 띠고 있고 코 드 파일 상태로 구성된다. 사양으로서은 Xxx.nc 모양을 나타내고 복잡화된 모양은 Xxxc.nc를 나타내고 있다.

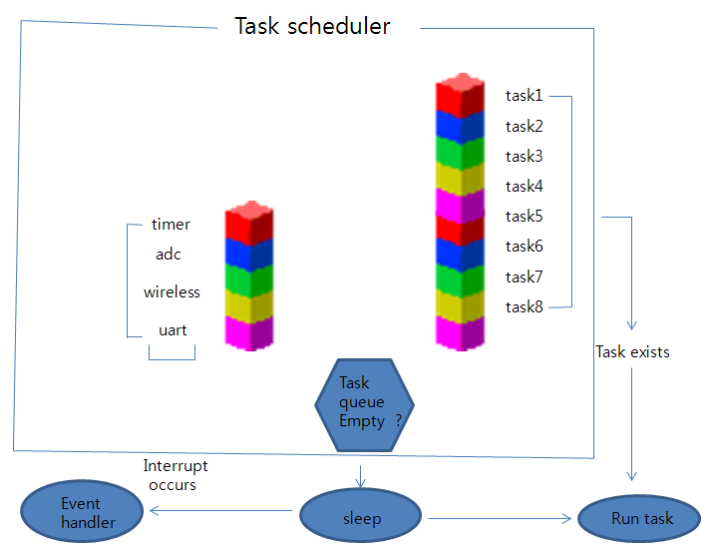

[Fig. 5] Schemetic of using model

이 모두가 와이어링 컴포넌트 구조 모양을 나타내고 있다. 인터페이스로서는 xxx.nc의 모양을 나타내고 커멘 드와 이벤트는 거리에 따라 다르게 나타난다.

\section{2 실험및 결과}

실험은 모의실험을 실시한다. 모의 실험은 LabVIEW 를 통해서 실시한다. LabVIEW를 시작하려면 LabVIEW 아이콘을 더블 클릭해서 실행하거나 실제 화면상에서 조 작하여 실시한다.

LabVIEW에서는 GPIB 인터페이스를 이용해서 계측 기의 제어를 수행할수도 있다. 이경우에는 퍼스컴에 $\mathrm{GPIB}$ 인터페이스 보드를 접속한다. 대표적인 GPIB구성 


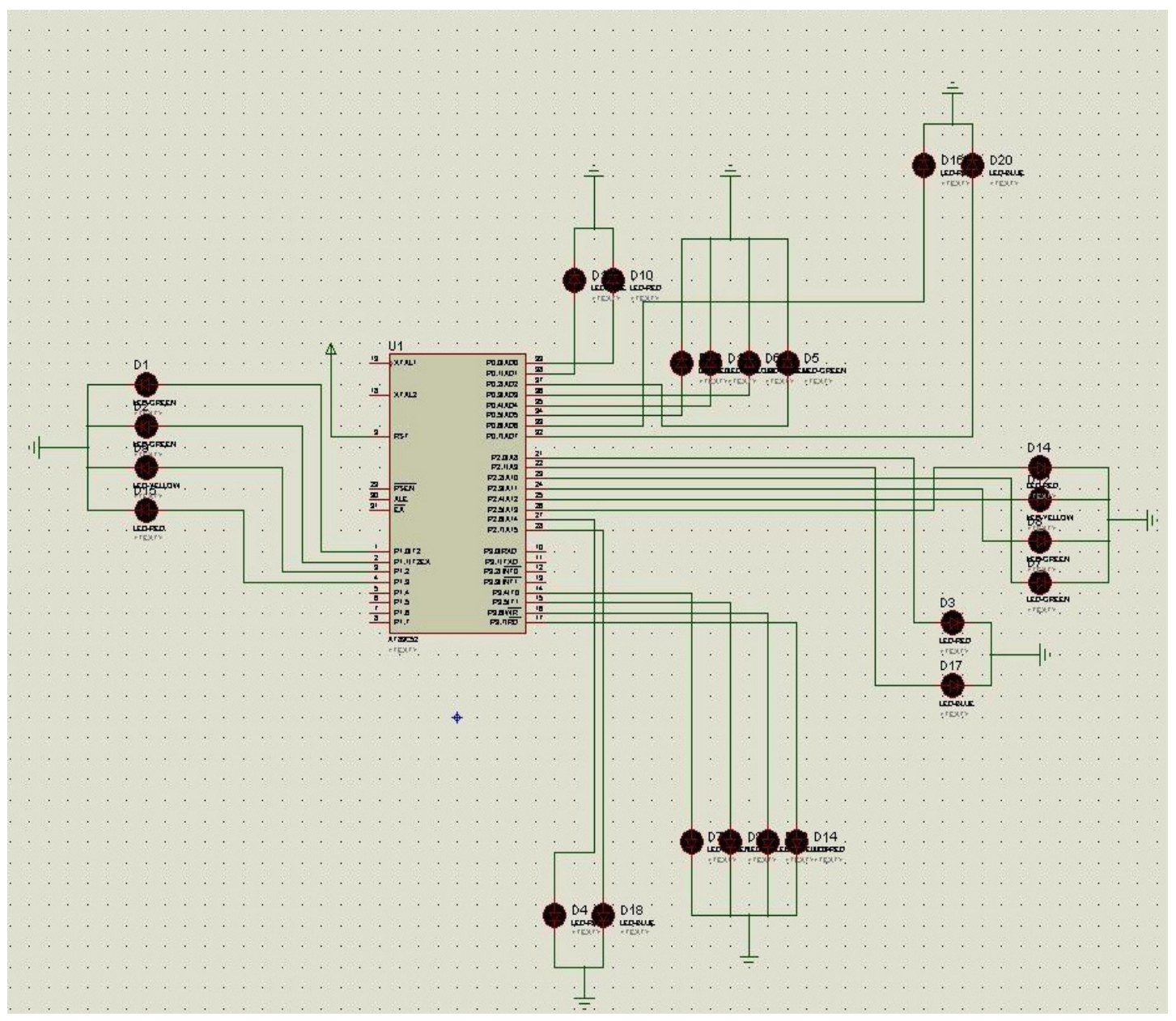

[Fig. 6] Microprocessor block diagram od traffic intersection

은 전형적인 GPIB선형구성과 별형(Star Configuration) 을 나타내고 다중 구성을 나타낸다.이외에 모터제어등 모션 컨트롤과 보드형 오실로스코프 등 풍부한 관련 제 품을 표시한다. LabVIEW는 사용가능한 기능의 차이로 부터 기본 패키지, 개발 시스템, 프로페셔날 개발 시스템 등 몇몇의 패키지로 구성되어 있다. 콘트롤은 데이터를 출력하는 터미널을 가진 객체와 노드이고, 프런트 패널 로부터 블록다이어그램으로 입력을 이동하게 하는 메커 니즘을 제공한다. 예를 들면, 토글스위치와 노브, 다이얼 등이 있다 한편 인디케이터는 데이터를 입력하는 터미널 을 갖는 객체와 노드들이고, 블록다이어그램에서 프런트 패널로 데이터를 표시하는 메커니즘을 제공한다. 예를 들면 구조란 프로그램의 흐름을 결정하는 제어 구조로서
LabVIEW에서 프로그램의 일부 또는 전체를 반복하여 실행할 경우와 조건에 따라 실행할 부분을 선택할 경우 에는 구조를 사용한다. 각종의 구조는 구조 서브 팔레트 에 저장되어 있다. 블록 다이어그램 윈도우 내에서 마우 스 오른쪽 버튼을 클릭하면 함수 팔레트 내의 구조 서브 팔레트를 표시한 화면이 나타난다. 대표적인 구조로는 케이스구조, 플랫 시퀀스 구조, 다층 시퀀스 구조, 이벤트 구조 타이밍 구조등이 있다. 배치한 컨트롤과 인디케이 터의 크기를 변경할 경우에는 객체를 선택한 후에 마우 스 포인터가 양방향 화살표로 되는 위치에서 드래그한다. 배치한 후에도 인디케이터를 컨트롤 또는 컨트롤을 인디 케이터로 변경할 수도 있다. 계통연계형 솔라보트 모니 터링 시스템의 파생효과는 LabVIEW 만이 갖는 특징이 
다[8].

\section{3 모의실험 과정}

IEEE 802.15.4 표준을 다양한 산업 응용에 사용하기 위해 제정중인 표준으로 홈네트워크와 유비 쿼터스 시대 에 가장 적합하다고 주목 받아온 새로운 무선 네트워크 기술인 Zigbee를 사용하여 시행하였다. 근거리 저전력 지향성 통신 기술이므로 반경 $30 \mathrm{~m}$ 내에서 $20^{2} 250 \mathrm{Kbps}$ 의 속도로 데이터를 전송하고 최대 255개의 로터리에 장착 하여 연결된 기기로 사용할 수 있으므로 이를 통하여 IEEE 802.15.4에서 정의된 물리계층과 MAC 계층과 더 불어 네트워크, 시큐리티, 응용 계층까지 표준화하고 있다 [9].

이표준은 ISM 주파수 스펙트럼을 간직하고 있다. 시 뮬레이션 과정은 AT89c51의 $\mathrm{CPU}$ 를 가지고 실현하였다. MSP430은 Texas Instrument 사에서 출시한 마이크로 컨트롤러 계열의 $\mathrm{MCU}$ 이다.

\begin{tabular}{|l|l|l|l|l|l|l|l|l|l|l|l|}
\hline ELF & VLF & LF & MW (MF) & HF & VHF & UHF & SHF & EHF & IR & UV & $x$ \\
Line
\end{tabular}

Hz $\mathrm{KH}^{2} \mathrm{KHz} \mathrm{MHz} \mathrm{MHz} \mathrm{MHz}$ GHz GHzGHz experiment

[Fig. 7] Simulation of channel width frequency

16 비트용 RISC 이며 작은 비용과 전력 소비가 아주 작다. 그래서 무선 $\mathrm{RF}$ 또는 배터리를 사용하는 전자기기 용으로 많이 사용되어 진다[10]. 센서 네트워크의 설계 요소로는 기능성을 들 수 있다. 이벤트 중심의 정확한 기 능 보장을 요구하고 어떤 이벤트가 다른 이벤트를 발생 시킬 경우에 side-effect가 최소화 되어야 한다. 두 번째 로는 확장성을 들수 있다. 센서노드가 증가하더라도 기 능및 성능 유지가 가능해야 한다. 이를 통한 결과로서는 다음 그래프를 들수 있는데 해당 교통량 증가에 따른 교 통의 증가 순서를 살펴 보더라도 해당그래프가 시간당 통과 차량수가 $\mathrm{x}$ 축 그래프이고 현시숫자가 $\mathrm{y}$ 축 그래프이 다. 따라서 해당 숫자의 증가수를 감안하더라도 교통량 의 증가에 따른 트래픽 숫자는 교통요소의 중요한 요소 가 되므로 센서노드를 통해서더라도 교통량 증가숫자를 더 늘려야 함을 알 수 있다. 자동차의 속도는 차량센서의 종류에 따라 증가함을 알 수 있다.

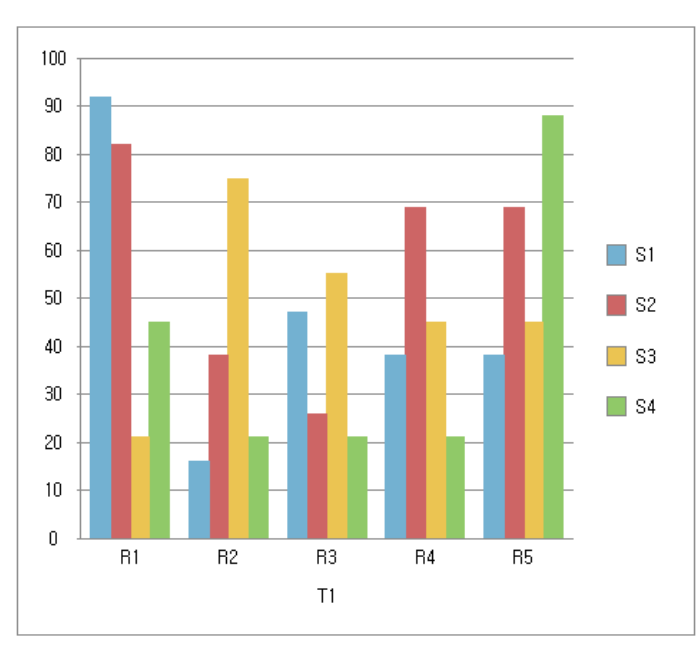

[Fig. 8] Result of simulation

\section{3. 결론}

센서노드를 통하여 교통량의 증가수를 크게 증가 시 키는 방법은 여러 가지 각도로서 모색되어져야한다. 이 는 하드웨어적이나 소프트웨어적으로도 가능하여야만 된다. 모의 실험 결과를 보더라도 가능 숫자가 현시수가 늘어나게 되면 교통량의 숫자가 크게 증가함을 알 수 있 다. 교통량이 증가하게 되면 해당 숫자가 늘어남을 알 수 있다. 이는 하드웨어적으로 저전력 소모기술이 이루어져 야 하고 다양한 센서를 위해 플렉시블한 $\mathrm{I} / \mathrm{O}$ 를 채택하여 야 하고 작은 크기를 가져야만 된다. 소프트웨어적으로 는 작고 간단한 코드를 유지하여야 하고 에너지 효율성 을 지원하여야 한다. 그러기 위해서는 스케쥴 정책과 라 우팅 프로토콜및 알고리즘을 개선해야만 한다.또한 교통 량의 병목 현상을 지양하여야하고 재사용성을 고려하여 야한다. 견고하고 저전력 하드웨어적인 고지향성을 견지 하여야 한다.이를 위해서 분산 알고리즘의 동적 수용을 소프트웨어적으로 시행을 하여야하고 다종 다양한 센서 및 구동기를 수용하여야 하고 분산 모니터링과 망관리를 시행하여야만 하는데 이는 중앙의 웹기반 모니터링 도구 를 두어서 실현하면 좋은 결과를 얻을수 있다.본논문을 사용하여 센서로서 이루어지지 않은 현 교통체계를 센서 위주로 이루는 내용으로 향후 교통체계에 많은 발전에 도움이 될 것이다. 


\section{ACKNOWLEDGMENTS}

This work was supported by Baekseok university research fund of 2014.

\section{REFERENCES}

[1] P.H. Westerink,D.E.Boekee,J.Biemond and J.W. Woods,"Subband Coding of Image Using Vector Quantization", IEEE transs.Commun., vol.36. pp.713-719. June 1988

[2] P.A.Chau,T.Lookabaugh,and R.M. Gray," EntropyConstrained Vector Quantization", IEEE Trans. Acoust.,Speech and Signal Process., vol. ASSP-37, pp.31-42,Jan.1989

[3] A.Gersho, "Asymptotically Optimal Block Quantization, "IEEE trans.Inform. Theory,vol. IT-27, pp.280-291,May 1981.

[4] J.W.Modestino and Y.H.Kim,"Adaptive EntropyCoded Predictive Vector Quanti zation of Images,"to appear in IEEE Trans. Acoust.,Speech, and Signal Process.,June 1992.

[5] Y.H.Kim and J.W.Modestino,"Adaptive EntropyCoded Pruned Tree-Structured Predictive Vector quantization of images," to appear in IEEE Trans. on Commun.

[6] J.B.Anderson,T.Aulin,andC.E.Sundberg, Digital Phase Modulation,Plenum Press, New York,1986

[7] Deepak Alur, Dan Malks, John Crupi, Core J2EE Patterns: Best Practices and Design Strategies, Sun Microsystems Press, 2003.

[8] Riehle, D., Zulighoven H., Understanding and Using Patterns of Object_Oriented Systems, 2(1), 1996.

[9] M.H. Lee, A Design of Database Tiers by using Design Patterns on X-Internet Environment for Plant Information, Journal of the Korean Institute of Plant Engineering, Vol. 10, No. 2, pp. 103-112, 2005.
진 현 수(Jin, Hyun Soo)

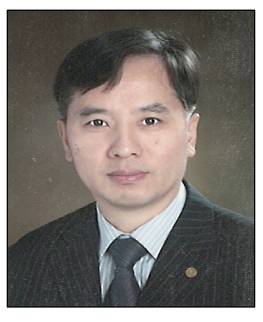

-1986년 2월 : 서울시립대학교 전자 공학(공학사)

-1993년 8월 : 서울시립대학교 전자 공학과 (공학 석사)

·2000년 2월 : 서울시립대학교 전자공 학과 공학 (공학박사)

·2001년 3월 현재 : 백석대학교 정 보통신학부 교수

· 관심분야 : 퍼지제어, 웹 콘트롤, 인터넷 통신

·E-Mail : jhs1020@bu.ac.kr 